\title{
Movement of Lip Corners
}

National Cancer Institute

\section{Source}

National Cancer Institute. Movement of Lip Corners. NCI Thesaurus. Code C87096.

During examination of the newborn infant, the examiner looks for symmetric movement

of the lip corners. Movement of the lip corners is governed by the zygomatic major

muscle. 